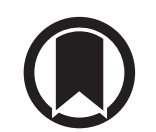

CrossMark

\section{Surveillance of adverse events in the treatment of drug-resistant tuberculosis: first global report}

Sergey Borisov ${ }^{1,69}$, Edvardas Danila ${ }^{2}$, Andrei Maryandyshev ${ }^{3}$, Margareth Dalcolmo ${ }^{4}$, Skaidrius Miliauskas ${ }^{5}$, Liga Kuksa ${ }^{6}$, Selene Manga ${ }^{7}$, Alena Skrahina ${ }^{8}$, Saulius Diktanas ${ }^{9}$, Luigi Ruffo Codecasa ${ }^{10}$, Alena Aleksa ${ }^{11}$, Judith Bruchfeld ${ }^{12,13,69}$, Antoniya Koleva ${ }^{14}$, Alberto Piubello 15,16,69, Zarir Farokh Udwadia ${ }^{17}$, Onno W. Akkerman ${ }^{18,19,69}$, Evgeny Belilovski', Enrique Bernal ${ }^{20}$, Martin J. Boeree ${ }^{21}$, Julen Cadiñanos Loidi ${ }^{22}$, Qingshan Cai ${ }^{23}$, Jose Joaquín Cebrian Gallardo ${ }^{24}$, Masoud Dara ${ }^{25}$, Edita Davidavičienè ${ }^{26,27}$, Lina Davies Forsman ${ }^{12,13}$, Jorge De Los Rios (10 ${ }^{28}$, Justin Denholm 29,30,69, Jacinta Drakšiené ${ }^{9}$, Raquel Duarte ${ }^{31}$, Seifeldin Eltaeb Elamin ${ }^{32}$, Nadia Escobar Salinas ${ }^{33}$, Maurizio Ferrarese ${ }^{10}$, Alexey Filippov ${ }^{1}$, Ana Garcia $^{34}$, José-María García-García (10 ${ }^{35}$, leva Gaudiesiute ${ }^{5}$, Blagovesta Gavazova ${ }^{36}$, Regina Gayoso ${ }^{4}$, Roscio Gomez Rosso ${ }^{37}$, Vygantas Gruslys ${ }^{2}$, Gina Gualano ${ }^{38}$, Wouter Hoefsloot (1021, Jerker Jonsson (1) ${ }^{39}$, Elena Khimova ${ }^{3}$. Heinke Kunst ${ }^{40}$, Rafael Laniado-Laborín ${ }^{41,69}$, Yang Li ${ }^{42}$, Cecile Magis-Escurra ${ }^{21}$, Vinicio Manfrin '(1) ${ }^{43}$, Valentina Marchese ${ }^{44}$, Elena Martínez Robles ${ }^{45}$, Alberto Matteelli ${ }^{44}$, Jesica Mazza-Stalder ${ }^{46,69}$, Charalampos Moschos ${ }^{47}$, Marcela Muñoz-Torrico ${ }^{48,69}$, Hamdan Mustafa Hamdan' ${ }^{32}$, Birute Nakčeriené ${ }^{26,27}$, Laurent Nicod ${ }^{46}$, Magnolia Nieto Marcos ${ }^{49}$, Domingo Juan Palmero ${ }^{34}$, Fabrizio Palmieri ${ }^{38}$, Apostolos Papavasileiou ${ }^{47}$, Marie-Christine Payen ${ }^{50}$, Agostina Pontarelli ${ }^{51}$, Sarai Quirós ${ }^{52}$, Adrian Rendon ${ }^{53}$, Laura Saderi ${ }^{54,69}$, Agnese Šmite ${ }^{6}$, Ivan Solovic ${ }^{55}$, Mahamadou Bassirou Souleymane ${ }^{16}$, Marina Tadolini ${ }^{56}$, Martin van den Boom ${ }^{25,69}$, Marisa Vescovo ${ }^{34}$, Pietro Viggiani ${ }^{51}$, Askar Yedilbayev ${ }^{25}$, Rolandas Zablockis ${ }^{2}$, Dmitry Zhurkin ${ }^{8}$, Matteo Zignol ${ }^{57}$, Dina Visca (108,59,69, Antonio Spanevello58,59, José A. Caminero ${ }^{60,61,69}$, Jan-Willem Alffenaarr $62,63,64,69$, Simon Tiberi ${ }^{40,65,69}$, Rosella Centis (106,69, Lia D’Ambrosio (10 ${ }^{67,69}$, Emanuele Pontali ${ }^{68,69}$, Giovanni Sotgiu $\mathbb{1}^{54,69}$ and Giovanni Battista Migliori (106,69

@ERSpublications

Previous evidence on adverse events is available from single studies. This global project (658 patients from 26 countries) demonstrates aDSM is feasible and serious adverse events of recommended drugs are reasonably low (overall 57 out of 504, 11.3\%). http://bit.ly/2kzvbqe

Cite this article as: Borisov S, Danila E, Maryandyshev A, et al. Surveillance of adverse events in the treatment of drug-resistant tuberculosis: first global report. Eur Respir J 2019; 54: 1901522 [https://doi.org/ 10.1183/13993003.01522-2019]. 
ABSTRACT The World Health Organization (WHO) recommends that countries implement pharmacovigilance and collect information on active drug safety monitoring (aDSM) and management of adverse events.

The aim of this prospective study was to evaluate the frequency and severity of adverse events to antituberculosis (TB) drugs in a cohort of consecutive TB patients treated with new (i.e. bedaquiline, delamanid) and repurposed (i.e. clofazimine, linezolid) drugs, based on the WHO aDSM project. Adverse events were collected prospectively after attribution to a specific drug together with demographic, bacteriological, radiological and clinical information at diagnosis and during therapy. This interim analysis included patients who completed or were still on treatment at time of data collection.

Globally, 45 centres from 26 countries/regions reported 658 patients $(68.7 \%$ male, $4.4 \%$ HIV coinfected) treated as follows: $87.7 \%$ with bedaquiline, $18.4 \%$ with delamanid ( $6.1 \%$ with both), $81.5 \%$ with linezolid and 32.4\% with clofazimine. Overall, 504 adverse event episodes were reported: 447 (88.7\%) were classified as minor (grade 1-2) and $57(11.3 \%$ ) as serious (grade 3-5). The majority of the 57 serious adverse events reported by 55 patients ( 51 out of $57,89.5 \%$ ) ultimately resolved. Among patients reporting serious adverse events, some drugs held responsible were discontinued: bedaquiline in $0.35 \%$ (two out of 577), delamanid in $0.8 \%$ (one out of 121), linezolid in 1.9\% (10 out of 536) and clofazimine in $1.4 \%$ (three out of 213) of patients. Serious adverse events were reported in $6.9 \%$ (nine out of 131) of patients treated with amikacin, $0.4 \%$ (one out of 221) with ethionamide/prothionamide, 2.8\% (15 out of 536) with linezolid and $1.8 \%$ (eight out of 498) with cycloserine/terizidone.

The aDSM study provided valuable information, but implementation needs scaling-up to support patient-centred care.

Affiliations: ${ }^{1}$ Moscow Research and Clinical Center for TB Control, Moscow Government's Health Department, Moscow, Russian Federation. ${ }^{2}$ Clinic of Chest Diseases, Immunology and Allergology, Vilnius University Medical Faculty, Centre of Pulmonology and Allergology, Vilnius University Hospital Santaros Klinikos, Vilnius, Lithuania. ${ }^{3}$ Northern State Medical University, Arkhangelsk, Russian Federation. ${ }^{4}$ Reference Center Hélio Fraga, Fundação Oswaldo Cruz (Fiocruz)/Ministry of Health, Rio de Janeiro, Brazil. ${ }^{5}$ Dept of Pulmonology, Lithuanian University of Health Sciences, Kaunas, Lithuania. ${ }^{6}$ MDR-TB Dept, Riga East University Hospital for TB and Lung Disease Centre, Riga, Latvia. ${ }^{7}$ Dept of Infectious Diseases, University National San Antonio Abad Cusco, Cusco, Peru. ${ }^{8}$ Republican Research and Practical Centre for Pulmonology and Tuberculosis, Minsk, Belarus. ${ }^{9}$ Tuberculosis Dept, 3rd Tuberculosis Unit, Republican Klaipeda Hospital, Klaipeda, Lithuania. ${ }^{10}$ TB Reference Centre, Villa Marelli Institute, Niguarda Hospital, Milan, Italy. ${ }^{11}$ Dept of Phthisiology and Pulmonology, Grodno State Medical University, Grodno, Belarus. ${ }^{12}$ Division of Infectious Diseases, Dept of Medicine, Karolinska Institute, Solna, Sweden. ${ }^{13}$ Dept of Infectious Diseases, Karolinska University Hospital, Stockholm, Sweden. ${ }^{14}$ Pulmonology and Physiotherapy Dept, Gabrovo Lung Diseases Hospital, Gabrovo, Bulgaria. ${ }^{15}$ Tuberculosis Division, International Union against Tuberculosis and Lung Disease (The Union), Paris, France. ${ }^{16}$ Tuberculosis Division, Damien Foundation, Niamey, Niger. ${ }^{17}$ Dept of Respiratory Medicine, P. D. Hinduja National Hospital and MRC, Mumbai, India. ${ }^{18}$ University of Groningen, University Medical Center Groningen, Dept of Pulmonary Diseases and Tuberculosis, Groningen, The Netherlands. ${ }^{19}$ University of Groningen, University Medical Center Groningen, TB Center Beatrixoord, Haren, The Netherlands. ${ }^{20}$ Unidad de Enfermedades Infecciosas, Hospital General Universitario Reina Sofia, Murcia, Spain. ${ }^{21}$ Radboud University Medical Center, Center Dekkerswald, Nijmegen, The Netherlands. ${ }^{22}$ Internal Medicine Dept, Hospital General de Villalba, Collado Villalba, Spain. ${ }^{23}$ Zhejiang Integrated Traditional and Western Medicine Hospital, Hangzhou, China. ${ }^{24}$ Unidad de Neumología, Agencia Sanitaria Costa del Sol, Marbella, Spain. ${ }^{25}$ World Health Organization Regional Office for Europe, Copenhagen, Denmark. ${ }^{26}$ National TB Registry, Public Health Dept, Ministry of Health, Vilnius, Lithuania. ${ }^{27}$ Vilnius University Hospital Santaros Klinikos, Vilnius, Lithuania. ${ }^{28}$ Centro de Excelencia de TB "Niño Jesus", Servicio de Neumologia, Hospital Maria Auxiliadora, Lima, Peru.

${ }^{29}$ Victorian Tuberculosis Program, Melbourne Health, Melbourne, Australia. ${ }^{30}$ Dept of Microbiology and Immunology, University of Melbourne, Melbourne, Australia. ${ }^{31}$ National Reference Centre for MDR-TB, Hospital Centre Vila Nova de Gaia, Dept of Pneumology, Public Health Science and Medical Education Dept, Faculty of Medicine, University of Porto, Porto, Portugal. ${ }^{32}$ MDR-TB Department, Abu anga Teaching Hospital, Khartoum, Sudan. ${ }^{33}$ Division of Disease Prevention and Control, Dept of Communicable Diseases, National Tuberculosis Control and Elimination Programme, Ministry of Health, Santiago, Chile. ${ }^{34}$ Pulmonology Division, Municipal Hospital F.J. Muñiz, Buenos Aires, Argentina. ${ }^{35}$ Tuberculosis Research Programme, SEPAR, Barcelona, Spain. ${ }^{36}$ "Improve the Sustainability of the National TB Programme", Sofia, Bulgaria. ${ }^{37}$ National Institute of Respiratory and Environmental Diseases "Prof. Dr. Juan Max Boettner" Asunción, Paraguay. ${ }^{38}$ Respiratory Infectious Diseases Unit, National Institute for Infectious Diseases "L. Spallanzani", IRCCS, Rome, Italy. ${ }^{39}$ Dept of Public Health Analysis and Data Management, Public Health Agency of Sweden, Solna, Sweden. ${ }^{40}$ Blizard Institute, Barts and The London School of Medicine and Dentistry, Queen Mary University of London, London, UK. ${ }^{41}$ Universidad Autónoma de Baja California, Baja California, Mexico; Clínica de Tuberculosis del Hospital General de Tijuana, Tijuana, Mexico. ${ }^{42}$ Dept of Infectious Diseases, Huashan Hospital, Fudan University, Shanghai, China. ${ }^{43} \mathrm{~S}$. Bortolo Hospital, Vicenza, Italy. ${ }^{44}$ Clinic of Infectious and Tropical Diseases, WHO Collaborating Centre for TB elimination and TB/HIV co-infection, University of Brescia, Brescia, Italy. ${ }^{45}$ Internal Medicine Dept, Tuberculosis Unit, Hospital de Cantoblanco - Hospital General Universitario La Paz, Madrid, Spain. ${ }^{46}$ Division of Pulmonary Medicine, University Hospital of Lausanne CHUV, Lausanne, Switzerland. ${ }^{47}$ Dept of Tuberculosis, Sotiria Athens Hospital of Chest Diseases, 


\section{Introduction}

With $>558000$ patients estimated by the World Health Organization (WHO) in 2017 [1], rifampicin- and multidrug-resistant tuberculosis (MDR-TB) are a clinical and public health priority $[1,2]$. From the public health perspective, it is imperative to prevent the selection of drug-resistant strains of Mycobacterium tuberculosis by effective treatment of drug-susceptible TB patients and to reduce the transmission of drug-resistant strains by diagnosing and treating them rapidly and effectively [3]. The clinical management of MDR- and extensively drug-resistant (XDR)-TB is expensive and medically challenging: clinicians are left with fewer effective drugs, which in turn cause more frequent serious adverse events than those used for the treatment of drug-susceptible TB $[1,2,4,5]$. Since the implementation of a global approach to treat MDR-TB with second-line drugs (known as the "DOTS Plus" strategy) [4], monitoring, recording and reporting of adverse events have become more important.

In recent years, new (i.e. delamanid and bedaquiline) and repurposed anti-TB drugs have been introduced in the treatment of MDR-TB [2]. Bedaquiline was recently included in the new WHO MDR-TB classification $[6,7]$ as a priority drug (group A) following growing evidence of efficacy and tolerability [8-14]. Delamanid is in the WHO group C (add-on agents) [6], with a promising safety profile [15-18].

The repurposed anti-TB drugs [6, 19] linezolid [20,21] and fluoroquinolones [19] have been included in group A, clofazimine in group B [22] and imipenem/meropenem in group C [23-25], based mainly on effectiveness studies, toxicity and programmatic considerations.

Although more evidence is becoming available from trials and observational studies on anti-TB drug toxicity, global active TB drug safety monitoring and management of adverse events (aDSM) information on the following is still missing: 1) new drugs; 2) linezolid and clofazimine; 3) drug combinations including drugs such as bedaquiline, delamanid, clofazimine and fluoroquinolones which increase the QT interval in the electrocardiogram (with possible life-threatening arrhythmias) [26, 27]; d) amikacin (group $\mathrm{C}$, and other second-line-injectable drugs), cycloserine/terizidone (group B), ethionamide/prothionamide, para-aminosalycilic acid (PAS), ethambutol, pyrazinamide (group C) and high dose-isoniazid [6, 19].

The WHO recommends pharmacovigilance and aDSM, inviting national TB programmes to implement "active and systematic clinical and laboratory assessment of patients on treatment with new TB medicines, or novel MDR-TB regimens in order to detect and report potential or confirmed drug toxicities" [28-30].

As of today, no global study has reported adverse events of anti-TB drugs based on a prospective aDSM approach including patients treated with the new drugs bedaquiline and delamanid and repurposed drugs such as linezolid and clofazimine.

This approach has been possible through the Global Tuberculosis Network [31], which recently reported the study design of the first aDSM project originally involving 27 countries [30].

Athens, Greece. ${ }^{48}$ Clínica de Tuberculosis, Instituto Nacional De Enfermedades Respiratorias Ismael Cosio Villegas, Ciudad De Mexico, Mexico. ${ }^{49}$ Internal Medicine Dept, Hospital Doctor Moliner, Valencia, Spain. ${ }^{50}$ Division of Infectious Diseases, CHU Saint-Pierre, Université Libre de Bruxelles (ULB), Brussels, Belgium. ${ }^{51}$ Reference Center for MDR-TB and HIV-TB, Eugenio Morelli Hospital, Sondalo, Italy. ${ }^{52}$ Pneumology Dept, Tuberculosis Unit, Hospital de Cantoblanco - Hospital General Universitario La Paz, Madrid, Spain. ${ }^{53}$ Centro de Investigación, Prevención y Tratamiento de Infecciones Respiratorias CIPTIR, University Hospital of Monterrey UANL (Universidad Autonoma de Nuevo Leon), Monterrey, Mexico. ${ }^{54}$ Clinical Epidemiology and Medical Statistics Unit, Dept of Medical, Surgical and Experimental Sciences, University of Sassari, Sassari, Italy. ${ }^{55}$ National Institute for TB, Lung Diseases and Thoracic Surgery, Vysne Hagy, Catholic University Ruzomberok, Ruzomberok, Slovakia. ${ }^{56}$ Unit of Infectious Diseases, Dept of Medical and Surgical Sciences Alma Mater Studiorum University of Bologna, Bologna, Italy. ${ }^{57}$ Global Tuberculosis Programme, World Health Organization, Geneva, Switzerland. ${ }^{58}$ Division of Pulmonary Rehabilitation, Istituti Clinici Scientifici Maugeri, IRCCS, Tradate, Italy. ${ }^{59}$ Dept of Medicine and Surgery, Respiratory Diseases, University of Insubria, Tradate, Italy. ${ }^{60}$ Pneumology Dept, Hospital General de Gran Canaria “Dr. Negrin”, Las Palmas de Gran Canaria, Spain. ${ }^{61}$ MDR-TB Unit, Tuberculosis Division, International Union against Tuberculosis and Lung Disease (The Union), Paris, France. ${ }^{62}$ University of Sydney, Faculty of Medicine and Health, School of Pharmacy, Sydney, Australia. ${ }^{63}$ Westmead Hospital, Sydney, Australia. ${ }^{64}$ University of Groningen, University Medical Center Groningen, Dept of Pharmacy and Pharmacology, Groningen, The Netherlands. ${ }^{65}$ Dept of Infection, Royal London and Newham Hospitals, Barts Health NHS Trust, London, UK. ${ }^{66}$ Servizio di Epidemiologia Clinica delle Malattie Respiratorie, Istituti Clinici Scientifici Maugeri IRCCS, Tradate, Italy. ${ }^{67}$ Public Health Consulting Group, Lugano, Switzerland. ${ }^{68} \mathrm{Dept}$ of Infectious Diseases, Galliera Hospital, Genova, Italy. ${ }^{69}$ These authors contributed equally.

Correspondence: Giovanni Battista Migliori, Servizio di Epidemiologia Clinica delle Malattie Respiratorie, Istituti Clinici Scientifici Maugeri IRCCS, Via Roncaccio 16, Tradate, Varese, 21049, Italy. E-mail: giovannibattista.miglioridicsmaugeri.it 
The aim of the present register-based study was to prospectively evaluate the frequency and severity of adverse events due to anti-TB drugs in a cohort of consecutive TB patients treated with new and repurposed drugs in 26 countries following the principles and methods of the WHO aDSM project [28$30,32]$. We summarise the findings of an interim analysis of patients who completed or were still on treatment at the time of data collection.

\section{Methods}

\section{Study design}

A pilot study was implemented in 2015 to assess feasibility and utility of the project as well as to pretest the data flow and analysis. The coordinating centre's ethics committee approved the study on July 11, 2017. The study was proposed to the clinical centres or national TB programmes participating in the network. Each centre or country signed a confidentiality and data-sharing agreement with the coordinating centre and obtained local ethics committee clearance or had a waiver indicating no requirement for ethical approval due to the local regulations.

Starting from July 2017 and after the participating centres signed up to the project, all consecutive patients (including children and adolescents) undergoing treatment with bedaquiline and/or delamanid were enrolled based on their drug exposure [30]. No specific exclusion criteria were adopted for patient selection. Mexico, Paraguay, Spain, Slovakia and Sudan started reporting when the first case in the country initiated anti-TB treatment with bedaquiline and/or delamanid.

The adverse events of any drug involved in the treatment regimen were prospectively collected, ensuring a probabilistic mechanism of causality assignment (e.g. attribution of the adverse event to a specific drug based on its evidence-based profile). Each clinical unit participating in the study had a consilium-like mechanism for the management of the adverse events [5]. All adverse events and the proposed attribution to one or more specific drugs were revised by the international coordination team and discussed with the reporting clinicians. The scientific evidence available during the study period drove the attribution of an adverse event to a specific drug based on a probability method. Any discrepancy was resolved by consensus. We contacted investigators to ensure accuracy after recoding and validation of the dataset before final analysis. The datasets reported by clinical centres and national TB programmes were updated twice a year. The present manuscript reports the results of the interim analysis conducted on the data reported up to August 28, 2019.

\section{Variables and definitions}

The data were obtained via a collection form in an electronic format based on the WHO-recommended template, although additional clinical details were requested [30]. Annual data collection occurs twice and is based on the information provided by the clinical files of the recruited clinical centres.

The information collected included anonymised patients' demographic data, bacteriological, radiological and clinical status at diagnosis, and data on treatment safety during therapy.

According to the WHO aDSM project, serious adverse events include death or a life-threatening event, hospitalisation or prolongation of hospitalisation, persistent or significant disability, or congenital anomaly. Serious adverse events included grade 3-5 adverse events (grade 3: serious; grade 4: life-threatening; grade 5: death) [13, 28, 32]. Minor adverse events included those of grade 1 (mild) and grade 2 (moderate) $[13,28,32]$.

Whenever an adverse event occurred, the clinicians reported it using a form summarising the adverse event details, including the grade, the $\operatorname{drug}(\mathrm{s})$ responsible (with details on the dosage and the accompanying medications), the examinations performed, the actions taken, the duration and the outcome of the event (recovered/resolved, recovering/resolving, with sequelae, not recovered/resolved, died, unknown).

All case definitions (e.g. MDR-TB, new case, retreatment case, etc.) were derived from WHO documents $[1,6,7]$.

The study coverage (annex 1; number of patients treated with new drugs reported/number of patients estimated) was defined in any country in agreement with the investigators and the national TB programme authorities [10].

\section{Data analysis}

A descriptive analysis was performed on the patients evaluated in the cohort. The analysis was stratified by geographical area (e.g. Europe versus non-Europe, where Europe refers to WHO European region and non-Europe to WHO regions other than Europe), sex, risk factors (e.g. HIV sero-status, diabetes) and adverse event severity. 
Qualitative and quantitative variables were summarised using absolute frequency, percentage median (interquartile ranges $(\mathrm{IQR})$ ) and mean $\pm \mathrm{SD}$. Chi-squared or Fisher exact tests were used to compare qualitative variables, and the t-test or Mann-Whitney test was used to statistically compare quantitative variables.

Adverse events were analysed both "per drug" (proportion of patients treated with a given drug who experienced an adverse event attributed to this drug) and by groups (organ/system) of adverse events according to a format allowing international comparisons [13].

The map in figure 1 was created using the ggplot2 and rworldmap packages in $\mathrm{R}$ version 3.5 .1 [10, 33].

\section{Results}

Overall, 45 centres from 26 countries/regions in all continents reported 658 patients as of August 28, 2019 (figure 1, annexes 1-3).

Argentina, Australia (Victoria State), Brazil, Bulgaria, Chile, China (Zhejiang Province), Greece, Lithuania, Mexico, the Netherlands, Niger, Paraguay, Portugal, Russian Federation (Moscow and Arkhangelsk Oblasts), Slovakia, Spain, Sudan, Sweden and Switzerland (Vaud county) reported $100 \%$ of the patients treated with new drugs in the country/region, while Belarus, Belgium, India, Italy, Latvia, Peru and the United Kingdom reported a proportion of national patients ranging from $15 \%$ to $80 \%$ (annex 1).

Demographic, epidemiological and clinical characteristics of the patients are summarised in table 1 (stratified by geographical area, Europe versus other than Europe). The adverse events per drug in cases who completed or were still under treatment are summarised in tables 2 and 3 (for each drug: number of patients with adverse events/number of patients treated with the drug) and in annex 3. The serious cardiological adverse events are summarised in table 4 (serious QT prolongation and serious arrhythmia) and the minor ones in annex 4. A summary of serious adverse events per organ/system is summarised in figure 2 and per drug in annex 5. The interval between drug administration and adverse event occurrence, according to the treatment outcome at the study data collection, is summarised in annex 6.

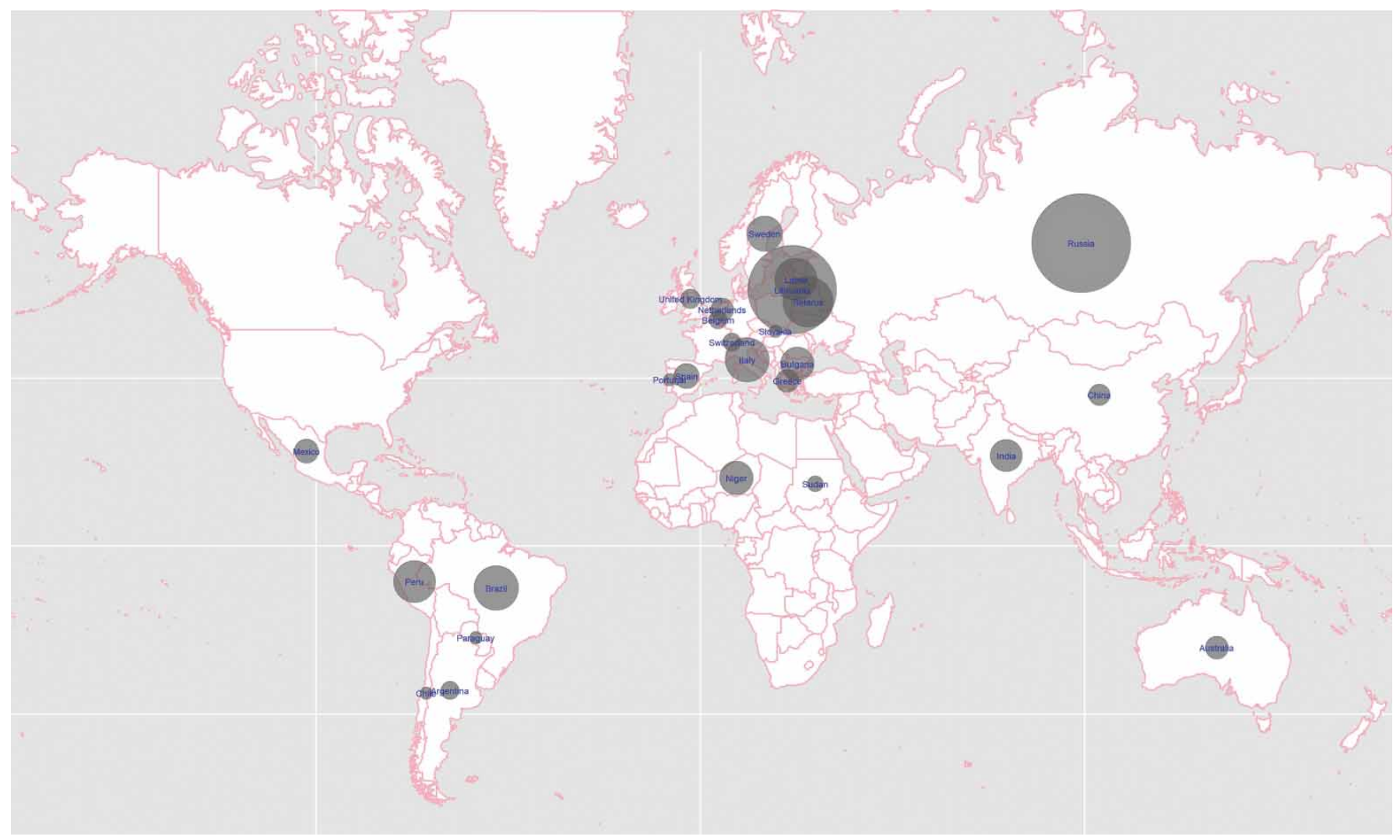

FIGURE 1 Global distribution of the clinical centres participating in the study. The size of the grey dots reflects the number of patients reported. 
TABLE 1 Descriptive analysis of the characteristics of 658 tuberculosis (TB) patients by area of origin (Europe versus other settings)

\begin{tabular}{|c|c|c|c|c|}
\hline & \multirow[t]{2}{*}{ Total } & \multicolumn{2}{|c|}{ Geographic area of origin } & \multirow[t]{2}{*}{ p-value } \\
\hline & & Non-European & European & \\
\hline Subjects & 658 & 120 & 538 & \\
\hline Male & 452/658 (68.7) & $80 / 120(66.7)$ & $372 / 538(69.1)$ & 0.60 \\
\hline Age years & $42(33-53)$ & $40.5(30-54)$ & $42.5(34-53)$ & 0.25 \\
\hline Body weight kg & $60(53-70)$ & $54.7(49.0-61.5)$ & $62(54-71)$ & $<0.0001$ \\
\hline Height $\mathrm{cm}$ & $173(165-178)$ & $167(160-174)$ & $174(168-178)$ & $<0.0001$ \\
\hline Migrant & $85 / 656(13.0)$ & $8 / 120(6.79)$ & $77 / 536(14.4)$ & 0.02 \\
\hline Pregnant & $5 / 347(1.4)$ & $2 / 72(2.8)$ & $3 / 275(1.1)$ & 0.28 \\
\hline Breastfeeding female & $2 / 326(0.6)$ & $2 / 66(3.0)$ & $0 / 260(0.0)$ & 0.04 \\
\hline Thyroid disease & $9 / 568(1.6)$ & $4 / 120$ (3.3) & $5 / 448(1.1)$ & 0.10 \\
\hline Patients with previous ECG abnormalities & $68 / 545(12.5)$ & $6 / 120(5.0)$ & $62 / 425(14.6)$ & 0.004 \\
\hline Alcohol abuser & $148 / 657(22.5)$ & $11 / 119(9.2)$ & $137 / 538(25.5)$ & $<0.0001$ \\
\hline Drug abuser & $41 / 658(6.2)$ & $6 / 120(5.0)$ & $35 / 538(6.5)$ & 0.54 \\
\hline Methadone user & $7 / 561(1.3)$ & $0 / 120(0.0)$ & $7 / 441(1.6)$ & 0.36 \\
\hline Patients with diabetes mellitus & $63 / 651(9.7)$ & $19 / 120(15.8)$ & 44/531 (8.3) & 0.02 \\
\hline People living with HIV & $29 / 655(4.4)$ & $0 / 120(0.0)$ & $29 / 535(5.4)$ & $<0.0001$ \\
\hline CD4 counts cells. $m^{-3}$ & $94(30-212)$ & & $94(30-212)$ & \\
\hline Patients on ART & $27 / 29(93.1)$ & $0 / 60(0.0)$ & $27 / 145(18.6)$ & $<0.0001$ \\
\hline Previous anti-TB treatment & $439 / 658(66.7)$ & $109 / 120(90.8)$ & $330 / 538(61.3)$ & $<0.0001$ \\
\hline Surgical therapy & $77 / 647(11.9)$ & $6 / 120(5.0)$ & $71 / 527(13.5)$ & 0.01 \\
\hline Pulmonary TB & $648 / 658(7.1)$ & $119 / 120(99.2)$ & $529 / 538(98.3)$ & 0.50 \\
\hline Extrapulmonary TB & $47 / 658(7.1)$ & $2 / 120(1.7)$ & $45 / 538(8.4)$ & 0.006 \\
\hline Sputum smear positive & $451 / 657$ (68.7) & $116 / 120(96.7)$ & $335 / 537(62.4)$ & $<0.0001$ \\
\hline Culture positive & $590 / 657(89.8)$ & $118 / 120$ (98.3) & 472/537 (87.9) & 0.001 \\
\hline
\end{tabular}

Data are presented as $n, n / N(\%)$ or median (interquartile range), unless otherwise stated. ART: antiretroviral therapy. ${ }^{\#}$ : non-European versus European.

Out of 658 patients, $577(87.7 \%)$ were treated with bedaquiline (which was co-administered with delamanid, in combination or sequentially, in 40 patients) and 121 (18.4\%) with delamanid: 161 (24.5\%) had TB caused by MDR-TB or rifampicin-resistant strains of M. tuberculosis, 224 (34\%) pre-XDR strains (125 MDR-TB with additional resistance to a fluoroquinolone and 99 to an injectable drug), 245 (38.6\%) XDR-TB strains, while 19 (2.9\%) presented different other resistances explaining the prescription of new drugs (including three pan-susceptible TB patients: two with serious adverse events to first-line drugs and one per clinical decision) (annex 2).

Most patients were male $(n=452,68.7 \%)$ and the median (IQR) age was $42(33-53)$ years. There were 85 (13.0\%) migrants. HIV co-infection was reported in 29 (4.4\%) out of 653 patients (three unknown status) with median (IQR) CD4 cell counts of $94(30-212)$ cells $\cdot \mathrm{mm}^{-3}$. The majority $(\mathrm{n}=27,93.1 \%)$ received antiretroviral therapy. A total of 47 (7.2\%) individuals were lost to follow-up.

Pulmonary TB was diagnosed in 648 (98.5\%) out of 658 patients, with 37 having involvement of both pulmonary and extrapulmonary sites and 10 with isolated extrapulmonary disease $(n=4$ lymph node, $n=3$ gastrointestinal, $\mathrm{n}=2$ pleural, $\mathrm{n}=1$ testicular and $\mathrm{n}=1$ psoas abscess).

The percentages of sputum smear- and culture-positive patients at diagnosis were $68.7 \%$ (451 out of 657) and $89.8 \%$ (590 out of 657), respectively; the remaining patients had a positive molecular test or were treated based on the resistance profile of the index case $(n=5)$, adverse events $(n=2)$ and clinical decision $(\mathrm{n}=1)($ annex 2).

The mean \pm SD number of drugs to which $M$. tuberculosis was resistant was $6.2 \pm 2.5$. Overall, $439(66.7 \%)$ out of 658 patients had been treated previously for TB.

The overall prevalence of drug resistance, related to the national drug resistance prevalence and sample size, was as follows: streptomycin $\mathrm{n}=415$ (86.3\%), pyrazinamide $\mathrm{n}=368$ (77.0\%), ethambutol $\mathrm{n}=476$ (75.1\%), fluoroquinolones $\mathrm{n}=385$ (61.9\%), ethionamide/prothionamide $\mathrm{n}=285$ (60.8\%), kanamycin $\mathrm{n}=315$ (52.9\%), capreomycin $\mathrm{n}=180(31.0 \%)$, amikacin $\mathrm{n}=171(30.3 \%)$, PAS $\mathrm{n}=86(23.1 \%)$, cycloserine/terizidone $\mathrm{n}=25(7.9 \%)$ and linezolid $\mathrm{n}=12(4.7 \%)$. 
TABLE 2 Serious (grade 3-5) and minor (grade 1-2) adverse events per drug in the overall cohort (658 tuberculosis (TB) patients)

\begin{tabular}{|c|c|c|c|c|c|c|}
\hline & \multicolumn{2}{|c|}{ Total adverse events } & \multicolumn{2}{|c|}{$\begin{array}{l}\text { Patients with serious } \\
\text { adverse events }\end{array}$} & \multicolumn{2}{|c|}{$\begin{array}{l}\text { Patients with minor } \\
\text { adverse events }\end{array}$} \\
\hline & $\mathrm{n}^{+}(\%)$ & $95 \% \mathrm{Cl}$ & $\mathrm{n}^{+}(\%)$ & $95 \% \mathrm{Cl}$ & $\mathrm{n}^{+}(\%)$ & $95 \% \mathrm{Cl}$ \\
\hline Subjects n & & & 52 & & 343 & \\
\hline Capreomycin & $52 / 187(27.8)$ & $21.4-34.2$ & $5 / 187(2.7)$ & $0.4-5.0$ & $47 / 187(25.1)$ & $18.9-31.3$ \\
\hline Amikacin & $30 / 131(22.9)$ & $15.7-30.1$ & $9 / 131(6.9)$ & $2.6-11.2$ & $21 / 131(16.0)$ & $9.7-22.3$ \\
\hline Ethionamide/prothionamide & $39 / 221(17.6)$ & $12.6-22.6$ & $1 / 221(0.4)$ & $-0.4-1.2$ & $38 / 221(17.2)$ & $12.2-22.2$ \\
\hline Pyrazinamide & $32 / 236(13.6)$ & $9.2-18.0$ & $1 / 236(1.7)$ & $0.0-3.4$ & $31 / 236(13.1)$ & $8.8-17.4$ \\
\hline Delamanid & $16 / 121(13.2)$ & $7.2-19.2$ & $1 / 121(0.8)$ & $-0.8-2.4$ & $15 / 121(12.4)$ & $6.5-18.3$ \\
\hline Linezolid & $69 / 536(12.9)$ & $10.1-15.7$ & $15 / 536(2.8)$ & $1.4-4.2$ & $54 / 536(10.1)$ & $7.6-12.7$ \\
\hline Bedaquiline & $64 / 577(11.1)$ & $8.5-13.7$ & $6 / 577(1.0)$ & $0.2-1.8$ & $58 / 577(10.1)$ & $7.6-12.6$ \\
\hline PAS & $24 / 215(11.2)$ & $7.0-15.4$ & $1 / 215(0.5)$ & $-0.4-1.4$ & $23 / 215(10.7)$ & $6.6-14.8$ \\
\hline Clofazimine & $15 / 213(7.0)$ & $3.6-10.4$ & $3 / 213(1.4)$ & $-0.2-3.0$ & $12 / 213(5.6)$ & $2.5-8.7$ \\
\hline Cycloserine/terizidone & $30 / 498(6.0)$ & $3.9-8.1$ & $8 / 498(1.8)$ & $0.5-2.7$ & $22 / 498(4.4)$ & $2.6-6.2$ \\
\hline Levofloxacin & $14 / 241(5.8)$ & $2.9-8.8$ & $0 / 241(0.0)$ & & $14 / 241(5.8)$ & $2.9-8.8$ \\
\hline Clarithromycin & $1 / 21(4.8)$ & $-4.3-13.9$ & $1 / 21(4.8)$ & $-4.3-13.9$ & $0 / 21(0.0)$ & \\
\hline Moxifloxacin & 9/240 (3.8) & $1.4-6.2$ & $1 / 240(0.4)$ & $-0.4-1.2$ & $8 / 240$ (3.3) & $1.0-5.6$ \\
\hline
\end{tabular}

PAS: para-aminosalicylic acid. ${ }^{\#}$ : cumulative frequency of adverse events occurred in patients treated with anti-TB drugs; ": in addition, three patients with serious adverse events due to all anti-TB drugs administered ( $n=2$ gastrointestinal, $n=1$ renal problem; table 4$) ;^{+}$: numerator is the number of patients who had at least an adverse event with the drug and denominator is the total number of patients treated with the drug: patients with adverse event per drug/number of patients treated with the drug (some patients may have had more than one adverse event per drug; table 4).

Treatment regimens included, in addition to bedaquiline and/or delamanid, linezolid (81.5\%), moxifloxacin $(37.1 \%)$, levofloxacin $(36.6 \%)$, clofazimine $(32.4 \%)$, capreomycin $(28.4 \%)$, amikacin $(19.9 \%)$ and carbapenems (11.2\%).

The median (IQR) range of the administrative delay in procuring bedaquiline was 0 (0-11) days.

TABLE 3 Serious (grade 3-5) and minor (grade 1-2) adverse events per drug in 233 tuberculosis (TB) patients who completed treatment

\begin{tabular}{|c|c|c|c|c|c|c|}
\hline & \multicolumn{2}{|c|}{ Total adverse events } & \multicolumn{2}{|c|}{$\begin{array}{l}\text { Severe adverse } \\
\text { events }\end{array}$} & \multicolumn{2}{|c|}{ Minor adverse events } \\
\hline & $\mathrm{n}^{\#}(\%)$ & $95 \% \mathrm{Cl}$ & $n(\%)$ & $95 \% \mathrm{Cl}$ & $n(\%)$ & $95 \% \mathrm{Cl}$ \\
\hline Subjects $\mathrm{n}$ & & & \multicolumn{2}{|c|}{20} & \multicolumn{2}{|l|}{176} \\
\hline Capreomycin & $27 / 80(33.8)$ & $23.4-44.2$ & $2 / 80(2.5)$ & $-0.9-5.9$ & $26 / 80(32.5)$ & $22.2-42.8$ \\
\hline Amikacin & $12 / 42(28.6)$ & $14.9-42.3$ & $3 / 42(7.1)$ & $-0.7-14.9$ & $11 / 42(26.2)$ & $19.9-39.5$ \\
\hline Ethionamide/prothionamide & $20 / 71(28.2)$ & $17.7-38.7$ & $1 / 71(1.4)$ & $-1.3-4.1$ & $19 / 71(26.8)$ & $16.5-37.1$ \\
\hline Pyrazinamide & $14 / 106(13.2)$ & $6.8-19.6$ & $1 / 106(0.9)$ & $-0.9-2.7$ & $12 / 106(11.3)$ & $5.3-17.3$ \\
\hline Delamanid & $10 / 43$ (23.3) & $10.7-35.9$ & $1 / 43(2.3)$ & $-2.2-6.8$ & $9 / 43(20.9)$ & $8.8-33.1$ \\
\hline Linezolid & $30 / 185(16.2)$ & $10.8-21.5$ & $5 / 185(2.7)$ & $0.4-5.0$ & $27 / 185(14.6)$ & $9.5-19.7$ \\
\hline Bedaquiline & $34 / 205(16.6)$ & $11.5-21.7$ & $2 / 205(1.0)$ & $-0.4-2.4$ & $32 / 205(15.6)$ & $10.6-20.6$ \\
\hline PAS & $11 / 102(10.8)$ & $4.8-16.8$ & $0 / 102(0.0)$ & & $11 / 102(10.8)$ & $4.8-16.8$ \\
\hline Clofazimine & $9 / 71(12.7)$ & $5.0-20.5$ & $1 / 71(1.4)$ & $-1.3-4.1$ & $8 / 71(11.3)$ & $3.9-18.7$ \\
\hline Cycloserine/terizidone & 14/178 (7.9) & $3.9-11.9$ & $3 / 178(1.7)$ & $-0.2-3.6$ & $11 / 178(6.2)$ & $2.7-9.7$ \\
\hline Levofloxacin & $6 / 88(6.8)$ & $1.5-12.1$ & $0 / 88(0.0)$ & & $6 / 88(6.8)$ & $1.5-12.1$ \\
\hline Clarithromycin & $1 / 9(11.1)$ & $-9.4-31.6$ & $1 / 9(11.1)$ & $-9.4-31.6$ & $0 / 9(0.0)$ & \\
\hline Moxifloxacin & $9 / 87(10.3)$ & $3.9-16.7$ & $0 / 87(0.0)$ & & $4 / 87(4.6)$ & $0.2-9.0$ \\
\hline
\end{tabular}

PAS: para-aminosalicylic acid. " : numerator is the number of patients who had at least an adverse event with the drug and denominator is the total number of patients treated with the drug: patients with adverse event per drug/number of patients treated with the drug (some patients may have had more than one adverse event per drug; table 4). 


\begin{tabular}{|c|c|c|c|c|c|c|c|c|c|c|c|c|c|c|}
\hline & Country & Age & Sex & $\begin{array}{c}\text { Drug } \\
\text { considered } \\
\text { responsible }\end{array}$ & $\begin{array}{l}\text { Current } \\
\text { prescribed } \\
\text { regimen }\end{array}$ & $\begin{array}{l}\text { Treatment } \\
\text { outcome }\end{array}$ & $\begin{array}{c}\text { Baseline } \\
\text { QTc } \\
\text { value } \\
\text { msec }\end{array}$ & $\begin{array}{l}\text { QTcF }_{\max } \\
\text { prolongation } \\
\text { reached } \\
\text { msec }\end{array}$ & $\begin{array}{c}\text { Episodels) } \\
n\end{array}$ & $\begin{array}{c}\text { Drug } \\
\text { permanently } \\
\text { interrupted }\end{array}$ & $\begin{array}{l}\text { If yes, } \\
\text { after } \\
\text { how } \\
\text { many } \\
\text { days }\end{array}$ & $\begin{array}{l}\text { Total } \\
\text { drug } \\
\text { exposure } \\
\text { days }\end{array}$ & $\begin{array}{l}\text { Drug } \\
\text { restarted }\end{array}$ & $\begin{array}{l}\text { Outcome: } \\
\text { adverse event } \\
\text { resolved/ } \\
\text { resolving }\end{array}$ \\
\hline \multirow[t]{8}{*}{ QT prolongation } & Italy & 41 & Male & Bdq & $\begin{array}{l}\text { Z, Cfz, Lzd, } \\
\text { Trd, Merop, } \\
\text { Clav, Bdq }\end{array}$ & $\begin{array}{l}\text { Still on } \\
\text { treatment }\end{array}$ & 454 & 480 & 1 & Yes & 190 & 190 & No & Resolved \\
\hline & Italy & 32 & Female & $\mathrm{Cfz}$ & $\begin{array}{l}\text { Cfz, PAS, } \\
\text { Trd, Amk, } \\
\text { Bdq, Lzd }\end{array}$ & $\begin{array}{l}\text { Still on } \\
\text { treatment }\end{array}$ & 454 & 500 & 1 & Yes & 23 & 23 & No & Resolved \\
\hline & Italy & 50 & Male & $\mathrm{Cfz}$ & $\begin{array}{l}\text { Mxf, Lzd, } \\
\text { Trd, Cfz, } \\
\text { Amk, Bdq }\end{array}$ & $\begin{array}{l}\text { Still on } \\
\text { treatment }\end{array}$ & 465 & 566 & 1 & Yes & 204 & 204 & No & Resolved \\
\hline & Lithuania & 35 & Female & $M f x^{\#, 9}$ & $\begin{array}{l}\text { Dlm, Lfx, } \\
\text { Mfx, Cm, } \\
\text { Lzd }\end{array}$ & $\begin{array}{l}\text { Still on } \\
\text { treatment }\end{array}$ & 352 & 618 & 1 & Yes & 11 & 11 & No & Resolved \\
\hline & Russia & 71 & Female & $\mathrm{Bdq}$ & $\begin{array}{l}\text { Bdq, Lzd, } \\
\text { Lfx, Cs, } \\
\text { Azitro, Cm }\end{array}$ & Cured & 354 & 556 & 1 & No & & 266 & Yes & Resolving \\
\hline & Russia & 55 & Female & Bdq & $\begin{array}{l}\text { Bdq, Lzd, } \\
\text { Lfx, Cs, } \\
\text { Azitro, Z }\end{array}$ & Cured & 341 & 527 & 1 & No & & 233 & Yes & Resolving \\
\hline & Russia & 73 & Female & Bdq & $\begin{array}{l}\text { Bdq, Lfx, } \\
\text { Cs, Cm, } \\
\text { PAS }\end{array}$ & $\begin{array}{l}\text { Still on } \\
\text { treatment }\end{array}$ & 338 & 521 & 1 & Yes & 84 & 84 & No & $\begin{array}{l}\text { Resolved } \\
\text { Resolving }\end{array}$ \\
\hline & Sweden & 33 & Female & $\mathrm{PAS}^{+}$ & $\begin{array}{l}\text { Bdq, Lfx, } \\
\text { Cs, Z, E, } \\
\text { Lzd, Cfz }\end{array}$ & $\begin{array}{l}\text { Still on } \\
\text { treatment }\end{array}$ & 438 & 530 & 1 & Yes & 17 & 17 & No & Resolved \\
\hline $\begin{array}{l}\text { VES-bigeminy } \\
\text { arrhythmia }\end{array}$ & Sweden & 59 & Male & Dlm & $\begin{array}{l}\text { Bdq, Cfz, } \\
\text { Lfx, Lzd, } \\
\text { Dlm }\end{array}$ & Cured & 393 & 420 & 1 & Yes & 4 & 4 & No & Resolved \\
\hline
\end{tabular}

QTc: corrected QT interval; QTCF: QT Fridericia-corrected QT interval; QT prolongation: an electrical disturbance visible on the ECG, measuring the delayed ventricular repolarisation, when the heart muscle takes longer than normal to recharge between beats; VES: ventricular extrasystole; Bdq: bedaquiline; Z: pyrazinamide; Cfz: clofazimine; Lzd: linezolid; Trd: terizidone; Merop: meropenem; Clav: clavulanic acid; PAS: para-aminosalicylic acid; Amk: amikacin; Mfx: moxifloxacin; Cm: capreomycin; Lfx: levofloxacin; Cs: cycloserine; Azitro: azitromycin; E: ethambutol; Dlm: delamanid. \#: Mfx was co-administered with delamanid; delamanid was well tolerated, with no adverse event reported; ๆ: Mfx was withdrawn after 231 days in a patient with Wolff-Parkinson-White syndrome: it was not considered as adverse event; ${ }^{+}$: PAS was responsible for diarrhoea, increased magnesium level and QT prolongation (which normalised after stopping the drug); ${ }^{\S}$ : after 2 months of treatment during pregnancy, linezolid and clofazimine were added after delivery. 


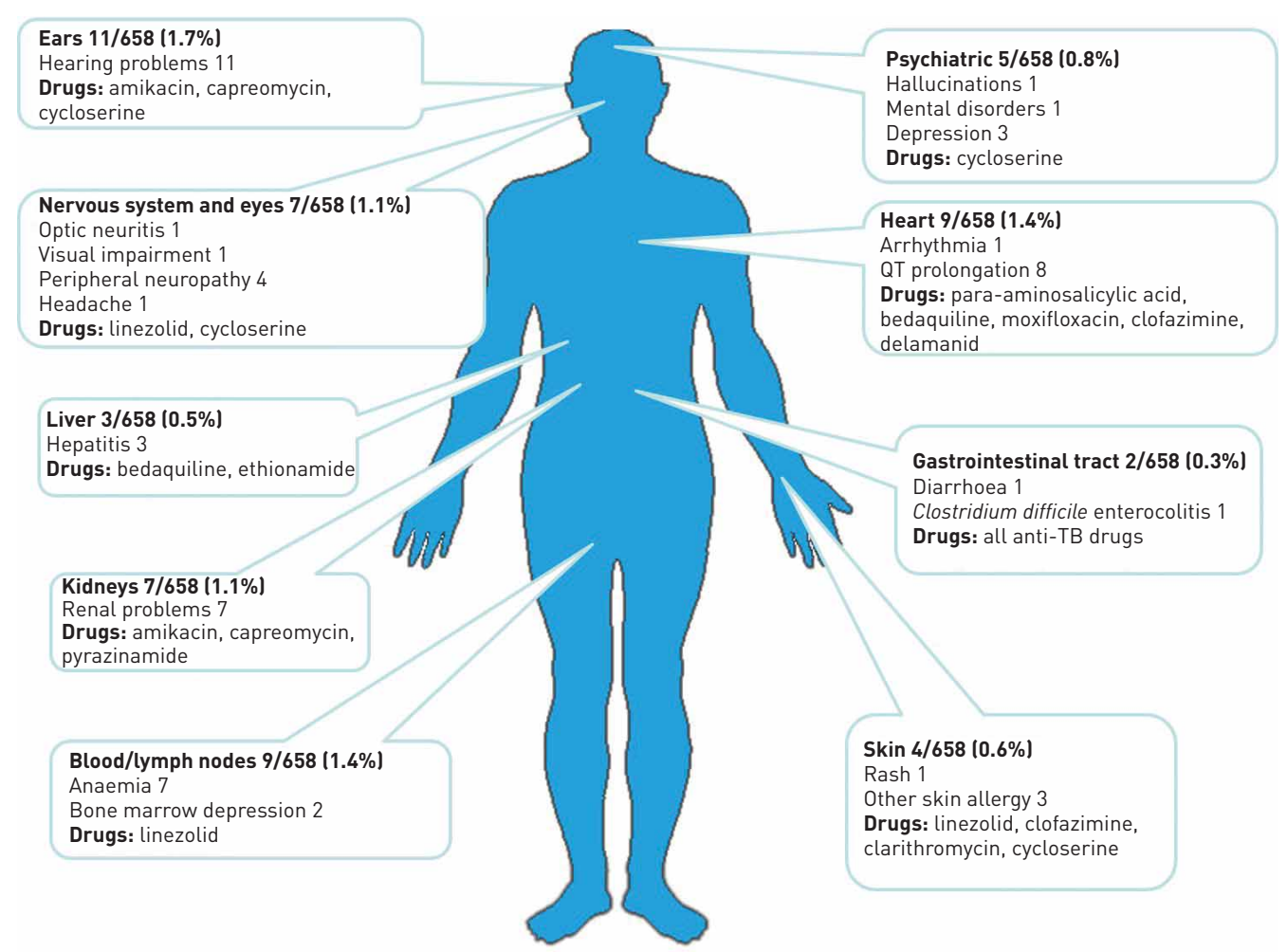

FIGURE 2 Summary of the distribution of 57 serious adverse events by organ/system.

Patients were exposed to bedaquiline for a median (IQR) of 170 (99-239) days, and to delamanid for 168 (145.5-182) days. Adjuvant surgical therapy and subsequent pulmonary rehabilitation were performed in 77 (11.9\%) patients.

The median (IQR) treatment duration in the cohort was 385 (231-545) days, including 233 (35.9\%) patients who completed treatment and 369 (56.7\%) who were still on treatment (150 (44.2\%) out of 339 having had 6 months of bedaquiline and 49 (67.1\%) out of 73 of delamanid) as of August 28, 2019.

\section{Adverse events}

Overall, 504 adverse event episodes were reported by clinical centres of which 447 (88.7\%) were classified as minor (grade 1-2) and 57 (11.3\%) were classified as serious (grade 3-5) (annex 5).

\section{Serious adverse events}

Overall, 57 (11.3\%) serious adverse events were reported by 55 patients for different organs/systems (table 2 and 3, annex 5), all resolved/resolving except six (10.5\%) as follows: $\mathrm{n}=2$ gastrointestinal, $\mathrm{n}=7$ nervous system, $\mathrm{n}=4$ skin, $\mathrm{n}=11$ hearing, $\mathrm{n}=5$ psychiatric, $\mathrm{n}=9$ blood, $\mathrm{n}=9$ cardiac, $\mathrm{n}=3$ hepatic and $\mathrm{n}=7$ renal (annex 3).

The overall proportion of patients reporting serious adverse events related to linezolid, clofazimine, bedaquiline and delamanid in patients treated with these medicines was 2.8\% (15 out of 536), 1.4\% (three out of 213 ), $1.0 \%$ (six out of 577 ) and $0.8 \%$ (one out of 121), respectively (table 2). Among patients who completed treatment the proportion of serious adverse events was (nonsignificantly) higher (table 3).

Clinicians reported to have notified the adverse events to the health authorities in their countries as follows: 3 (52.6\%) out of 57 serious and 19 (4.3\%) out of 447 minor adverse events.

\section{Cardiological adverse events}

Overall, $17(2.6 \%)$ out of 658 patients experienced a Fridericia-corrected QT prolongation (QTcF) $\geqslant 500 \mathrm{msec}$. Among them, 16 received bedaquiline (six with serious and 10 with minor adverse events; two of them with co-administered delamanid). In a single case, treated with delamanid alone, a serious adverse event was reported and attributed to moxifloxacin (table 4). 
A QTcF interval prolongation causing serious cardiological adverse events was reported by eight patients only (table 4); the drug responsible was bedaquiline in four patients, clofazimine in two patients, moxifloxacin and PAS in one patient, while in another patient it was due to a non-TB drug (amitriptyline, data not shown). No deaths were recorded. Out of those who received bedaquiline, the drug was withdrawn only in two patients reporting serious adverse events (two (0.35\%) out of 577), while in two patients the QT normalised after interrupting the concomitant administration of clofazimine. All serious QT-related adverse events resolved/are resolving.

A single patient had one minor adverse event related to QTcF prolongation requiring withdrawal of the drug (moxifloxacin replaced by levofloxacin) (annex 4).

Overall, 32 patients experienced minor adverse events related to QT prolongation, the majority due to bedaquiline ( $n=28,87.5 \%)$ and fluoroquinolones ( $n=3,9.3 \%)$ (annex 4).

A single patient discontinued delamanid after experiencing a serious adverse event (ventricular bigeminy arrhythmia appearing 4 days into treatment) (table 4 ).

\section{Discussion}

The aim of the present study was to prospectively evaluate the frequency and severity of adverse events due to anti-TB drugs in a cohort of consecutive patients following the principles and methods of the WHO aDSM project.

The project worked as a "register" according to the WHO proposal to national programmes, aimed at promoting regular monitoring of adverse events, as well as collecting and reporting information on bacteriological status at diagnosis, during and at the end of treatment with final outcomes [7, 29, 30]. WHO recommends that countries use their existing surveillance methodology (electronic registers or existing electronic medical record systems) to extract the data and use them for clinical and public health purposes [29].

National TB programmes face difficulties in implementing aDSM and contributing to the global database. While the amount and type of information to collect is known and there is a sufficient burden of patients to satisfy the need to establish a routine adverse event recording and reporting system, the existing surveillance systems are currently not equipped to collect and analyse relevant variables.

The present project represents the first effort to document the feasibility of the aDSM approach and to collect quality scientific evidence on the adverse events in patients treated with new and repurposed drugs in "field conditions" in countries from all continents. The available scientific evidence on the safety and tolerability profile of anti-TB drugs can be retrieved from single observational and experimental studies. This project provides an international assessment following a register-based methodology.

A first important finding of the study is that when treatment regimens including bedaquiline and delamanid are used, the overall proportion of adverse events is reasonably low $(8.7 \%$ of patients with serious adverse events (grade 3 and 4, no grade 5 adverse events)).

Notably, the injectables (and ethionamide) are the drugs causing more adverse events (table 2 and 3 ). With the new WHO all-oral approach $[6,7]$ and the availability of new drugs, capreomycin will no longer be used, and amikacin as well as ethionamide/prothionamide (and PAS) will be used less. In contrast, linezolid will be used increasingly, and being a drug with frequent and serious adverse events [20] there is a need to balance efficacy and toxicity [34]. Therapeutic drug monitoring may help achieve a therapeutic target of area under the curve/minimal inhibitory concentration $>119$ [35] while keeping trough concentrations low enough to prevent toxicity [36].

A second important outcome of this study is the possibility to carefully analyse the adverse events caused by bedaquiline and delamanid and by repurposed drugs. While overall $11.1 \%$ of the patients had adverse events to bedaquiline and $13.2 \%$ to delamanid (table 2), the serious adverse events due to these drugs were few, with only two patients discontinuing bedaquiline $(0.35 \%)$ and one discontinuing delamanid $(0.8 \%)$ because of cardiological adverse events [14,37].

The proportion of patients reporting serious adverse events related to linezolid- and clofazimine-treated patients was $3 \%$ and $1.4 \%$, respectively (annex 3 ).

Overall, 5.8\% of the patients experienced an adverse event with levofloxacin and $3.8 \%$ with moxifloxacin, while only two patients had serious adverse events with moxifloxacin at the normal dose. None of the 12 patients treated with high-dose isoniazid and high-dose moxifloxacin reported adverse events.

Worryingly, an important proportion of adverse events identified by care providers were not reported to health authorities at the national level. We speculate that the explanations for the adverse event 
under-reporting include lack of awareness, the administrative burden (need to report to the country and to the aDSM system and to the drug manufacturer with different forms and multiple steps), confidentiality issues, the involvement of different sectors (public and private, prisons, etc.) and the fear of blame.

Furthermore, there were a few discrepancies on grading of the adverse event "QTc prolongation". In four patients the adverse events were initially categorised as minor, even though they had resulted in the withdrawal of the offending drug. In agreement with the treating physician these adverse events were reclassified as serious. Asymptomatic conditions such as QTc prolongation need clear and well publicised criteria for accurate grading. QTc interval monitoring is usually performed in MDR-TB patients exposed to bedaquiline and delamanid in the WHO European region; although rare fatal events have been recorded, the ECG is a cost-effective preventive intervention for those at risk of developing cardiological adverse events [38].

To avoid premature discontinuation of potent drugs, available national and or international expert panels could be consulted for guidance [5, 31]. Medical conditions which can significantly increase the probability of a cardiological adverse event in MDR-TB patients (i.e. hypokalaemia and AIDS) should be monitored carefully [39].

When compared with the recent individual data meta-analysis performed in five cohorts (Armenia, Georgia, South Africa, France and Janssen Therapeutic cohort) on 537 patients treated with bedaquiline under compassionate use [13], the proportion of adverse events seems rather consistent with those found in our study. For example, $4.9 \%$ of patients suffered cardiac adverse events in the five-cohort study similar to the $5.5 \%$ in our study (denominator: patients treated with bedaquiline). Similarly, the proportion of interruptions of bedaquiline treatment in our study due to QTcF increase $(0.35 \%)$ is consistent with that described in a recent systematic review of the literature (0.68\%) [26].

The study has several strengths, including the number of countries participating [26] and a large sample size (to our knowledge one of the largest multinational cohorts of MDR-TB patients treated with bedaquiline- and/or delamanid-containing regimens based on WHO aDSM protocol), the prospective design and the accuracy of the information collected in countries with different epidemiological and economic backgrounds. Last, but not least, the majority of countries/states/regions (21 out of 26) provided data on all the consecutive patients treated with bedaquiline and delamanid during the study period.

A limitation is represented by the use of a consensus-based process to attribute adverse events to a specific drug, which included the local expert panel and the aDSM International Group panel. The scientific evidence on the safety and tolerability profile of a single drug or of a pharmacological combination was the driver adopted to identify the drug responsible of an adverse event; the probability of proving a causal relationship in specific patients, where the scientific evidence is poor, is very low. Further studies focused on the anti-TB drugs' safety, based on the re-challenge methodology (i.e. drug administration after interruption following the occurrence of an adverse event) could help elucidate the adverse event profile of the anti-TB drugs. Furthermore, only a few centres carried out therapeutic drug monitoring to assess the relationship between adverse events and drug exposure (dosage and frequency of administration). Moreover, no variables related to concomitant medications, which could affect drug exposure, were recorded, with HIV therapy in patients with HIV infection the only exception. It was not possible to use approaches like the Naranjo score or the Yale algorithm [40,41]. A second limitation is that few paediatric patients (four individuals aged $<18$ years) and people living with $\operatorname{HIV}(\mathrm{n}=29,4.4 \%$ ) were included in the cohort to allow specific subanalyses.

The psychological role played by providing information on the risk of treatment failure following drug withdrawal, as well as potential biased communication with migrants and the clinical setting (e.g. ambulatory care), could have affected the patients' tolerability profile and the reporting of adverse events. Unfortunately, we did not collect any variables which could evaluate those important features.

Furthermore, we evaluated the occurrence of adverse events in both individuals completing their regimen and still on treatment, for whom the cumulative drug toxicity (e.g. from linezolid) may be underestimated. Among patients who completed treatment, where the cumulative toxicity can be adequately assessed, the proportion of adverse events was (nonsignificantly) higher.

We did not collect any genetic/pharmacogenomic data, which could increase the risk of some adverse events. Future studies are needed to better clarify the role played by host and environmental characteristics in the occurrence of adverse events.

Finally, as the majority of countries started their aDSM project with this study, preselection or under-notification of adverse events (particularly minor ones and those not related to the new drugs) cannot be excluded. The under-reporting in a real-world setting can be a key issue in estimating the safety profile of a drug/pharmacological regimen. Healthcare workers and patients should be aware of the 
importance of reporting the occurrence of adverse events to better understand the pharmacological safety and the benefit/risk ratio of a prescription. A classification bias of some adverse events should be considered: although all clinical centres enrolled in the project followed the WHO protocol on adverse events' reporting, local audits aimed at assessing the implementation of the standard operating procedures (e.g. regular audiometry) were not carried out because of financial constraints.

Unfortunately, several countries (in America, Asia and sub-Saharan Africa) declined when asked to participate, in view of the voluntary basis of the study perceived as "difficult" or "time-consuming" without provision for additional resources. For this reason, and because of the different entry time in the study (which works as a "register"), the study does not allow us to evaluate the prevalence of drug resistance in the different settings. There is an urgent need to overcome the administrative burden involved in reporting adverse event by easy-to-use e-forms that can be automatically compiled from medical records.

The study will continue to evaluate early and final treatment outcomes as periodic updates occur and the "cohort" is therefore a "living" one. This cohort allows evaluation of novel treatments and combinations in a relatively short time-frame; particularly important given the substantial variation in international practice and guidelines recommending person-centred therapy for MDR-TB [42, 43].

This approach will allow the participating countries to evaluate the "quality" of their treatment services and minimise the risk of post-treatment sequelae responsible of functional damage and impaired quality of life [44-46].

In conclusion, the study results confirm that aDSM for patients undergoing anti-TB regimens with new drugs is feasible. Furthermore, the study reaffirms the relative safety of new drugs recommended by the new WHO guidelines, as the occurrence of serious adverse events in this large cohort of patients from 26 countries was observed in $<10 \%$ of patients. Greater adoption of the recommended aDSM at a local, national and international level is possible by improving the quality of the process (i.e. standardised, active and regular recording and reporting based on shared standard operating procedures).

Acknowledgements: The authors wish to thank Algirdas Gauronskis, Vita Globyte (Clinic of Tuberculosis and Pulmonology, Republican Šiauliai County Hospital, Šiauliai, Lithuania), Antanas Strazdas (Dept of Tuberculosis, Alytus County Tuberculosis Hospital, Alytus, Lithuania) and Paola Castellotti (Regional TB Reference Centre, Villa Marelli Institute, Niguarda Hospital, Milan, Italy) for their contributions.

Author contributions: The manuscript was conceived, planned, written, edited and approved using a collaborative approach, following the internal GTN (Global Tuberculosis Network) and internationally acknowledged rules on authorship, based on major intellectual contribution to the steps mentioned above. The study represents a global effort involving 26 countries in all continents. G. Sotgiu, S. Tiberi, R. Centis, L. D’Ambrosio and G.B. Migliori wrote the protocol. G. Sotgiu, L. Saderi and R. Duarte revised it for methodological content. G. Sotgiu, L. Saderi, R. Centis and L. D’Ambrosio performed the analysis. S. Tiberi, R. Centis, L. D’Ambrosio, E. Pontali, J-W. Alffenaar, J.A. Caminero, G. Sotgiu and G.B. Migliori wrote the first draft of the manuscript. S. Borisov, J. Bruchfeld, A. Piubello, O.W. Akkermann, J. Denholm, J-M. García-García, R. Laniado-Laborín, J. Mazza-Stalder, A. Matteelli, M. Muñoz-Torrico, M. van den Boom, D. Visca, J.A. Caminero and G. Sotgiu wrote the sections of the manuscript (second draft). A. Spanevello, J-M. García-García, Z.F. Udwadia, E. Danila, A. Maryandyshev and M. Dalcolmo provided comments to the second draft (third draft). A. Maryandyshev, S. Miliauskas, L. Kuksa, S. Manga, A. Skrahina, S. Diktanas, L.R. Codecasa, A. Aleksa, A. Koleva, E. Belilovski, E. Bernal, M.J. Boeree, J. Cadiñanos Loidi, Q. Cai, J.J. Cebrian Gallardo, M. Dara, E. Davidavičienė, L. Davies Forsman, J. De Los Rios, S.E. Elamin, N. Escobar Salinas, M. Ferrarese, A. Filippov, B. Gadzheva, A. Garcia, R. Gayoso, R. Gomez Rosso, V. Gruslys, G. Gualano, W. Hoefsloot, J. Jonsson, E. Khimova, H. Kunst, Y. Li, C. Magis-Escurra, V. Manfrin, V. Marchese, E. Martínez Robles, C. Moschos, H. Mustafa Hamdan, B. Nakčerienè, L. Nicod, M. Nieto Marcos, D.J. Palmero, F. Palmieri, A. Papavasileiou, M-C. Payen, A. Pontarelli, S. Quirós, A. Rendon, L. Saderi, A. Šmite, I. Solovic, M.B. Souleymane, M. Tadolini, M. Vescovo, P. Viggiani, A. Yedilbayev, R. Zablockis, D. Zhurkin and M. Zignol provided additions to the fourth draft. S. Tiberi and J. Denholm proofread the manuscript. All co-authors approved the final manuscript.

Conflict of interest: S. Borisov has nothing to disclose. E. Danila has nothing to disclose. A. Maryandyshev has nothing to disclose. M. Dalcolmo has nothing to disclose. S. Miliauskas has nothing to disclose. L. Kuksa reports personal fees for trial participation from Otsuka and Tibotec, personal fees for lectures from Johnson and Johnson Services Inc., outside the submitted work. S. Manga has nothing to disclose. A. Skrahina has nothing to disclose. S. Diktanas reports personal fees for trial participation from Otsuka, grants for meeting attendance from Janssen (Sirturo), outside the submitted work. L.R. Codecasa has nothing to disclose. A. Aleksa has nothing to disclose. J. Bruchfeld has nothing to disclose. A. Koleva has nothing to disclose. A. Piubello has nothing to disclose. Z.F. Udwadia has nothing to disclose. O.W. Akkerman has nothing to disclose. E. Belilovski has nothing to disclose. E. Bernal has nothing to disclose. M.J. Boeree has nothing to disclose. J. Cadiñanos Loidi has nothing to disclose. Q. Cai has nothing to disclose. J.J. Cebrian Gallardo has nothing to disclose. M. Dara has nothing to disclose. E. Davidavičiene has nothing to disclose. L. Davies Forsman has nothing to disclose. J. De Los Rios has nothing to disclose. J. Denholm has nothing to disclose. J. Drakšiene has nothing to disclose. R. Duarte has nothing to disclose. S.E. Elamin has nothing to disclose. N. Escobar Salinas has nothing to disclose. M. Ferrarese has nothing to disclose. A. Filippov has nothing to disclose. A. Garcia has nothing to disclose. J.M. García-García has nothing to disclose. I. Gaudiesiute has nothing to disclose. B. Gavazova has nothing to disclose. R. Gayoso has nothing to disclose. R. Gomez Rosso has nothing to disclose. V. Gruslys has nothing 
to disclose. G. Gualano has nothing to disclose. W. Hoefsloot has nothing to disclose. J. Jonsson has nothing to disclose. E. Khimova has nothing to disclose. H. Kunst has nothing to disclose. R. Laniado-Laborín has nothing to disclose. Y. Li has nothing to disclose. C. Magis-Escurra has nothing to disclose. V. Manfrin has nothing to disclose. V. Marchese has nothing to disclose. E. Martínez Robles has nothing to disclose. A. Matteelli has nothing to disclose. J. Mazza-Stalder has nothing to disclose. C. Moschos has nothing to disclose. M. Muñoz-Torrico has nothing to disclose. H. Mustafa Hamdan has nothing to disclose. B. Nakčerienè has nothing to disclose. L. Nicod has nothing to disclose. M. Nieto Marcos has nothing to disclose. D.J. Palmero has nothing to disclose. F. Palmieri has nothing to disclose. A. Papavasileiou has nothing to disclose. M-C. Payen has nothing to disclose. A. Pontarelli has nothing to disclose. S. Quirós has nothing to disclose. A. Rendon has nothing to disclose. L. Saderi has nothing to disclose. A. Šmite has nothing to disclose. I. Solovic has nothing to disclose. M.B. Souleymane has nothing to disclose. M. Tadolini has nothing to disclose. M. van den Boom has nothing to disclose. M. Vescovo has nothing to disclose. P. Viggiani has nothing to disclose. A. Yedilbayev has nothing to disclose. R. Zablockis has nothing to disclose. D. Zhurkin has nothing to disclose. M. Zignol has nothing to disclose. D. Visca has nothing to disclose. A. Spanevello has nothing to disclose. J.A. Caminero has nothing to disclose. J-W. Alffenaar has nothing to disclose. S. Tiberi has nothing to disclose. R. Centis has nothing to disclose. L. D’Ambrosio has nothing to disclose. E. Pontali has nothing to disclose. G. Sotgiu has nothing to disclose. G.B. Migliori has nothing to disclose.

Support statement: The project is supported by the Global Tuberculosis Network (GTN; Committees on TB Treatment, Clinical Trials and Global TB Consilium) and was part of the European Respiratory Society Latin American project in collaboration with ALAT (Asociación Latino Americana de Torax - Latino American Thoracic Association) and SBPT (Brazilian Society of Pulmonology and Tuberculosis). This article belongs to the scientific activities of the WHO Collaborating Centre for Tuberculosis and Lung Diseases, Tradate, ITA-80, 2017-2020- GBM/RC/LDA.

\section{References}

1 World Health Organization (WHO). Global Tuberculosis Report 2018. Geneva, WHO, 2018. Document WHO/ CDS/TB/2018.20.

2 Pontali E, Raviglione MC, Migliori GB, et al. Regimens to treat multidrug-resistant tuberculosis: past, present and future perspectives. Eur Respir Rev 2019; 28: 190035.

3 Migliori GB, Nardell E, Yedilbayev A, et al. Reducing tuberculosis transmission: a consensus document from the World Health Organization Regional Office for Europe. Eur Respir J 2019; 53: 1900391.

4 Nathanson E, Gupta R, Huamani P, et al. Adverse events in the treatment of multidrug-resistant tuberculosis: results from the DOTS-Plus initiative. Int J Tuberc Lung Dis 2004; 8: 1382-1384.

5 Tiberi S, Pontali E, Tadolini M, et al. Challenging MDR-TB clinical problems - the case for a new Global TB Consilium supporting the compassionate use of new anti-TB drugs. Int J Infect Dis 2019; 80S: S68-S72.

6 World Health Organization (WHO). WHO Consolidated Guidelines on Drug-Resistant Tuberculosis Treatment. Geneva, WHO, 2019. WHO/CDS/TB/2019.3.

7 Migliori GB, Global Tuberculosis Network (GTN). Evolution of programmatic definitions used in tuberculosis prevention and care. Clin Infect Dis 2019; 68: 1787-1789.

8 Diacon AH, Pym A, Grobusch MP, et al. Multidrug-resistant tuberculosis and culture conversion with bedaquiline. N Engl J Med 2014; 371: 723-732.

9 Pym AS, Diacon AH, Tang SJ, et al. Bedaquiline in the treatment of multidrug- and extensively drug-resistant tuberculosis. Eur Respir J 2016; 47: 564-574.

10 Borisov SE, Dheda K, Enwerem M, et al. Effectiveness and safety of bedaquiline-containing regimens in the treatment of MDR- and XDR-TB: a multicentre study. Eur Respir J 2017; 49: 1700387.

11 Pontali E, Sotgiu G, D’Ambrosio L, et al. Bedaquiline and multidrug-resistant tuberculosis: a systematic and critical analysis of the evidence. Eur Respir J 2016; 47: 394-402.

12 Pontali E, D'Ambrosio L, Centis R, et al. Multidrug-resistance tuberculosis and beyond: an updated analysis of the current evidence on bedaquiline. Eur Respir J 2017; 49: 1700146.

13 Mbuagbaw L, Guglielmetti L, Hewison C, et al. Outcomes of bedaquiline treatment in patients with multidrug-resistant tuberculosis. Emerg Infect Dis 2019; 25: 936-943.

14 Ndjeka N, Schnippel K, Master I, et al. High treatment success rate for multidrug-resistant and extensively drug-resistant tuberculosis using a bedaquiline-containing treatment regimen. Eur Respir J 2018; 52: 1801528.

15 Gler MT, Skripconoka V, Sanchez-Garavito E, et al. Delamanid for multidrug-resistant pulmonary tuberculosis. N Engl J Med 2012; 366: 2151-2160.

16 Kim CT, Kim TO, Shin HJ, et al. Bedaquiline and delamanid for the treatment of multidrug-resistant tuberculosis: a multicentre cohort study in Korea. Eur Respir J 2018; 51: 1702467.

17 Kuksa L, Barkane L, Hittel N, et al. Final treatment outcomes of multidrug and extensively drug-resistant tuberculosis patients in Latvia receiving delamanid-containing regimens. Eur Respir J 2017; 50: 1701105.

18 Mohr E, Hughes J, Reuter A, et al. Delamanid for rifampicin-resistant tuberculosis: a retrospective study from South Africa. Eur Respir J 2018; 51: 1800017.

19 Collaborative Group for the Meta-Analysis of Individual Patient Data in MDR-TB treatment-2017, Ahmad N, Ahuja SD, et al. Treatment correlates of successful outcomes in pulmonary multidrug-resistant tuberculosis: an individual patient data meta-analysis. Lancet 2018; 392: 821-834.

20 Sotgiu G, Centis R, D'Ambrosio L, et al. Efficacy, safety and tolerability of linezolid containing regimens in treating MDR-TB and XDR-TB: systematic review and meta-analysis. Eur Respir J 2012; 40: 1430-1442.

21 Tang S, Yao L, Hao X, et al. Efficacy, safety and tolerability of linezolid for the treatment of XDR-TB: a study in China. Eur Respir J 2015; 45: 161-170.

22 Dalcolmo M, Gayoso R, Sotgiu G, et al. Effectiveness and safety of clofazimine in multidrug-resistant tuberculosis: a nationwide report from Brazil. Eur Respir J 2017; 49: 1602445.

23 Tiberi S, Payen MC, Sotgiu G, et al. Effectiveness and safety of meropenem/clavulanate-containing regimens in the treatment of MDR- and XDR-TB. Eur Respir J 2016; 47: 1235-1243. 
24 Tiberi S, Sotgiu G, D'Ambrosio L, et al. Comparison of effectiveness and safety of imipenem/clavulanate- versus meropenem/clavulanate-containing regimens in the treatment of MDR- and XDR-TB. Eur Respir J 2016; 47: $1758-1766$.

25 Tiberi S, Sotgiu G, D’Ambrosio L, et al. Effectiveness and safety of imipenem-clavulanate added to an optimized background regimen (OBR) versus OBR control regimens in the treatment of multidrug-resistant and extensively drug-resistant tuberculosis. Clin Infect Dis 2016; 62: 1188-1190.

26 Pontali E, Sotgiu G, Tiberi S, et al. Cardiac safety of bedaquiline: a systematic and critical analysis of the evidence. Eur Respir J 2017; 50: 1701462.

27 Pontali E, Sotgiu G, Tiberi S, et al. Combined treatment of drug-resistant tuberculosis with bedaquiline and delamanid: a systematic review. Eur Respir J 2018; 52: 1800934.

28 World Health Organization (WHO). Active TB Drug-Safety Monitoring and Management (aDSM). WHO/HTM/ TB/2015.28. Geneva, WHO, 2015.

29 Halleux CM, Falzon D, Merle C, et al. The World Health Organization global aDSM database: generating evidence on the safety of new treatment regimens for drug-resistant tuberculosis. Eur Respir J 2018; 51: 1701643.

30 Akkerman O, Aleksa A, Alffenaar JW, et al. Surveillance of adverse events in the treatment of drug-resistant tuberculosis: a global feasibility study. Int J Infect Dis 2019; 83: 72-76.

31 Rossato Silva D, Rendon A, Alffenaar JW, et al. Global TB Network: working together to eliminate tuberculosis. J Bras Pneumol 2018; 44: 347-349.

32 U.S. Department of Health and Human Services, National Institutes of Health, National Cancer Institute. Common Terminology Criteria for Adverse Events (CTCadverse event) Version 5.0, November 2017. Date last accessed: July 28, 2019. https://ctep.cancer.gov/protocolDevelopment/electronic_applications/docs/CTCAE_v5_ Quick_Reference_8.5x11.pdf.

33 R Core Team. R: A language and environment for statistical computing. Vienna, Austria, R Foundation for Statistical Computing, 2018. Data last accessed: July 28, 2019. www.R-project.org

34 Bolhuis MS, Akkerman OW, Sturkenboom MGG, et al. Linezolid-based regimens for multidrug-resistant tuberculosis (TB): a systematic review to establish or revise the current recommended dose for TB treatment. Clin Infect Dis 2018; 67: Suppl. 3, S327-S335.

35 Srivastava S, Magombedze G, Koeuth T, et al. Linezolid dose that maximizes sterilizing effect while minimizing toxicity and resistance emergence for tuberculosis. Antimicrob Agents Chemother 2017; 61: e00751-17.

36 Song T, Lee M, Jeon HS, et al. Linezolid trough concentrations correlate with mitochondrial toxicity-related adverse events in the treatment of chronic extensively drug-resistant tuberculosis. EBioMedicine 2015; 2: $1627-1633$.

37 von Groote-Bidlingmaier F, Patientia R, Sanchez E, et al. Efficacy and safety of delamanid in combination with an optimised background regimen for treatment of multidrug-resistant tuberculosis: a multicentre, randomised, double-blind, placebo-controlled, parallel group phase 3 trial. Lancet Respir Med 2019; 7: 249-259.

38 Guglielmetti L, Tiberi S, Burman M, et al. QT prolongation and cardiac toxicity of new tuberculosis drugs in Europe: a Tuberculosis Network European Trialsgroup (TBnet) study. Eur Respir J 2018; 52: 1800537.

39 Monedero-Recuero I, Hernando-Marrupe L, Sánchez-Montalvá A, et al. QTc and anti-tuberculosis drugs: a perfect storm or a tempest in a teacup? Review of evidence and a risk assessment. Int J Tuberc Lung Dis 2018; 22: $1411-1421$.

40 Naranjo CA, Busto U, Sellers EM, et al. A method for estimating the probability of adverse drug reactions. Clin Pharmacol Ther 1981; 30: 239-245.

41 Kramer MS, Hutchinson TA. The Yale algorithm. Special workshop - clinical. Drug Inf J 1984; 18: 283-291.

42 Nunn AJ, Phillips PPJ, Meredith SK, et al. A trial of a shorter regimen for rifampin-resistant tuberculosis. $N$ Engl $J$ Med 2019; 380: 1201-1213.

43 Churchyard GJ. A short regimen for rifampin-resistant tuberculosis. N Engl J Med 2019; 380: 1279-1280.

44 Muñoz-Torrico M, Rendon A, Centis $\mathrm{R}$, et al. Is there a rationale for pulmonary rehabilitation following successful chemotherapy for tuberculosis? J Bras Pneumol 2016; 42: 374-385.

45 Tiberi S, Torrico MM, Rahman A, et al. Managing severe tuberculosis and its sequelae: from intensive care to surgery and rehabilitation. J Bras Pneumol 2019; 45: e20180324.

46 Visca D, Zampogna E, Sotgiu G, et al. Pulmonary rehabilitation is effective in patients with tuberculosis pulmonary sequelae. Eur Respir J 2019; 53: 1802184. 